\section{Fast Forward in MS}

\author{
By Lev Osherovich, Senior Writer
}

Fast Forward LLC, a not-for-profit venture firm spun out of the National Multiple Sclerosis Society in the U.S., has partnered with EMD Serono Inc. to fill the funding gap between preclinical research and drug development at pharma companies. The deal will enable Fast Forward to boost its investments in early-stage biotech companies.

EMD Serono is the U.S. division of Merck Serono S.A., which is a subsidiary of Merck KGaA. Under the arrangement, announced earlier this month, EMD Serono will invest up to \$15 million over the next 5 years in projects selected by Fast Forward and will pay $\$ 4$ million directly to Fast Forward to manage the program. In return for funding, Merck KGaA will receive a right to first negotiation on IP resulting from funded projects.

The partnership thus represents a significant boost in capital for Fast Forward, which has been receiving $\$ 3$ million annually from the National MS Society since the venture unit was founded in 2007. To date, the firm has invested in two companies.

Last December, Fast Forward added $\$ 1$ million to a $€ 10$ million (\$13.5 million) series A round for Apitope International N.V. to develop the company's MS vaccine technology. Other investors in the round were LRM N.V., Hasselt University, Vesalius Biocapital Partners sàrl and Vlaams InnovatieFonds.

Earlier this month, Fast Forward signed a sponsored research agreement with Provid Pharmaceuticals Inc. to finance preclinical development of PV-267, an immunomodulatory small molecule. Provid will receive $\$ 50,000$ in exchange for warrants.

\section{Warrant driven}

Although technically a not-for-profit firm, Fast Forward operates like a traditional VC and will share in the upside from its investments, said CEO Timothy Coetzee. "Our preferred instrument is the warrant, which allows us to buy equity in the future," he said.

According to Coetzee, Fast Forward's warrants are less dilutive than the direct equity, royalty agreements or cash multiples favored by other venture philanthropy organizations and thus make the companies more attractive to other investors in subsequent funding rounds.

Coetzee emphasized that as an affiliate of the MS Society, Fast Forward's primary aim is to advance technology for patients. "The point is not to create a revenue stream, though if this happens, that's great," he said.
For its part, EMD Serono gets to leverage Fast Forward's access to disease expertise via its MS Society roots and the firm's willingness to take early-stage development risk. "By working with us, EMD Serono identifies technology that it can in-license," said Coetzee.

Conversely, for biotech companies and early investors, Coetzee said the advantage of Fast Forward financing is that "you've pre-identified a development partner and an exit strategy" in the form of EMD Serono. "If you sign up with us, EMD Serono will have an opportunity to continue funding you for further development," he said.

Ewen Sedman, SVP of research at Merck Serono, said the Fast Forward deal will help the company find early-stage products with different modes of action than products already in the company's pipeline.

Together with Pfizer Inc., EMD Serono markets Rebif interferon- $\beta 1 \mathrm{a}$ to treat relapsing-remitting MS (RRMS), and has Mylinax, an oral formulation of cladribine, in Phase III trials for MS.

According to Sedman, EMD Serono is particularly interested in modulators of innate and adaptive immunity, neuroprotective therapies and cellular and molecular approaches to nerve repair and remyelination.

Fast Forward and EMD Serono have put out a request for proposals in these areas and aim to invest $\$ 3$ million this year in increments of up to $\$ 500,000$, said Sedman.

\section{Science portfolio}

-Timothy Coetzee,

Fast Forward LLC

Apitope CEO Keith Martin said Fast Forward's investment is earmarked for a Phase II trial of ATX-MS-1467, a peptide therapeutic designed to elicit a protective immune response against MS.

The company was already negotiating to partner the ATX-MS-1467 trial with EMD Serono when Fast Forward's financing cemented the pharma's involvement in the project.

"The Fast Forward deal came through at around the same time as Serono," said Martin. "Had that not happened, we would have been working with typical VC backing. We had a good series of events, but Fast Forward was a critical enabler for us."

Sedman noted that EMD Serono and Fast Forward independently decided to fund Apitope. "Fast Forward's funding of Apitope predated our collaborative agreement with Fast Forward and will continue independently of our licensing agreement with Apitope," he said.

In Provid's case, the custom medicinal chemistry company is developing PV-267 in collaboration with Thomas Forsthuber, professor of immunology at the University of Texas at San Antonio. According to Coetzee, the Fast Forward money will supplement a Small Business Innovation Research (SBIR) grant to the company.

PV-267 is an inhibitor of the major histocompatibility complex class II DR2 (HLA-DR2) variant, which has been linked to MS in a majority of patients. The compound is in preclinical development.

"We're helping underwrite a collaboration between Forsthuber and the Provid team, connecting an MS expert to medicinal chemists," said Coetzee "It's a niche project that fits between academic and clinical development." 


\section{TRANSLATIONAL NOTES}

\section{Philanthropy plus}

Fast Forward's model contrasts with the approach taken by the Myelin Repair Foundation (MRF), which has assembled a virtual institute of leading researchers to concentrate on one specific aspect of MS, the regeneration of damaged nerve tissue.

"We don't make venture capital investments in companies," said MRF president Scott Johnson. "We leave that to true venture capitalists."

Johnson thinks Fast Forward occupies a niche later in the development pipeline than MRF, which is primarily focused on basic research and bringing animal models and assays for MS up to a level suitable for industry.

According to Johnson, most MS therapies in the pipeline are immunomodulators that aim to prevent further nerve deterioration rather than restoring nerve function. He hopes that with philanthropic investment, myelin repair technologies eventually can be brought to the point where they would warrant investment by traditional VCs.

MRF's funding has thus far gone mostly to academic researchers and has generated new IP from which the foundation receives royalties. Johnson said MRF now plans to work with companies that take up the foundation's technology but did not provide details of how such arrangements would be financed.
Coetzee thinks there's room for multiple strategies to stimulate MS research. He noted that Fast Forward's work is complementary to the more focused efforts of MRF.

"Our friends at MRF are interested in identifying new targets, and we could imagine licensing some of them in the future," Coetzee said. "It's definitely not a winner-takes-all game. We're not trying to outdo the big venture capital firms and pharmas."

Osherovich, L. SciBX 2(21); doi:10.1038/scibx.2009.858

Published online May 28, 2009

COMPANIES AND INSTITUTIONS MENTIONED

Apitope International N.V., Hasselt, Belgium

EMD Serono Inc., Rockland, Mass.

Fast Forward LLC, New York, N.Y.

Hasselt University, Diepenbeek, Belgium

LRM N.V., Hasselt, Belgium

Merck KGaA (Xetra:MRK), Darmstadt, Germany

Merck Serono S.A., Geneva, Switzerland

Myelin Repair Foundation, Saratoga, Calif.

National Multiple Sclerosis Society, New York, N.Y.

Pfizer Inc. (NYSE:PFE), New York, N.Y.

Provid Pharmaceuticals Inc., New Brunswick, N.J.

University of Texas at San Antonio, San Antonio, Texas

Vesalius Biocapital Partners sàrl, Luxembourg

Vlaams InnovatieFonds, Brussels, Belgium 